\title{
EVALUANDO LA SOSTENIBILIDAD DE LAS ÁREAS DE CAPTACIÓN DE AGUA POTABLE EN LA REGIÓN DEL BIOBÍO A TRAVÉS DE UN ÍNDICE DE VULNERABILIDAD
}

\section{ASSESSING THE SUSTAINABILITY OF DRINKING WATER CATCHMENT AREAS IN THE BIOBIO REGION THROUGH A VULNERABILITY INDEX}

Rodrigo Peña Sebald ', Gerardo Azócar García ${ }^{2}$, Carolina Baeza Freer ${ }^{3}$

RESUMEN: La disponibilidad de agua potable cada día tiene mayor incertidumbre, la demanda de agua es creciente y la oferta del recurso hídrico es limitada. Esto nos lleva a plantear la siguiente interrogante: ¿Qué tan lejos estamos de sobrepasar la capacidad medioambiental para la generación de agua? Indudablemente, una pregunta compleja, difícil de responder y que requiere, según el contexto territorial, geográfico, ecológico y económico un enfoque metodológico integrado y la construcción de indicadores que permitan evaluar la sostenibilidad de las Áreas de Captación de Agua Potable len adelante ACAP) de la región del Biobío. La ACAP, es aquella parte de la cuenca que surte de agua cruda a una instalación sanitaria, que dota de agua potable a una localidad. En este estudio se realizó una propuesta de indicadores para evaluar la sustentabilidad de las ACAP, para lo cual se aplicó Análisis Multicriterio, Sistema de Información Geográfico, actividades de terreno y consulta a expertos. La metodología en este estudio se centró en la forma de combinar varios criterios, variables y supuestos, para formular un índice integrado de evaluación de las ACAP. Se propuso nueve indicadores que permitieron evaluar, de manera integrada, la sostenibilidad de las ACAP frente a diversos factores forzantes asociados, cada uno de ellos, al sistema económico, productivo, social y de infraestructura regional. Los resultados indican que el 30\% de las ACAP analizadas poseen vulnerabilidad alta y muy alta.

Palabras clave: ACAP, Biobío, índice, vulnerabilidad, sostenibilidad

Recibido: 13.03.21 Aceptado: 27.05.21

1 Magíster Ciencias Regionales, UDEC, rpenasebald@gmail.com, hitps:orcid.org/0000-0002-5996-9647 2 Facultad de Ciencias Ambientales y Centro EULA, UDEC, gazocar@udec.cl,

hitps:orcid.org/0000-0003-3595-4528

3 Facultad de Ciencias Ambientales y Centro EULA, UDEC, anabaeza@udec.cl,

https:orcid.org/0000-0002-5568-364 1 
ABSTRACT: The availability of drinking water is increasingly uncertain, the demand for water is growing and the supply of water resources is limited. This leads us to ask the following question: How far are we from exceeding the environmental capacity for water generation? Undoubtedly, a complex question that is difficult to answer and that requires, according to the territorial, geographical, ecological and economic context, an integrated methodological approach and the construction of indicators or indices that allow evaluating the sustainability of the Drinking Water Catchment Areas (in hereinafter ACAP) of the Biobio region. The ACAP is that part of the basin that supplies raw water to a sanitary facility, which provides drinking water to a town. In this study, a proposal of indicators was made to evaluate the sustainability of the ACAP, for which Multicriteria Analysis, Geographic Information System, field activities and expert consultation were applied. The methodology in this study focused on how to combine various criteria, variables, and assumptions to formulate an integrated ACAP evaluation index. Nine sub-indices were proposed that made it possible to evaluate, in an integrated manner, the sustainability of the ACAPs in the face of various forcing factors associated each one of them, to the economic, productive, social and regional infrastructure system. The results indicate that $30 \%$ of the ACAPs analyzed were high and very high vulnerability.

Key words: ACAP, Biobío, index, vulnerability, sustainability

\section{INTRODUCCIÓN}

El acceso al agua se reconoce, desde hace algún tiempo, como un derecho humano (Asamblea de la Organización de las Naciones Unidas, 2010, p. 3). La agenda 2030 para el desarrollo sostenible de la Comisión Económica para América Latina y el Caribe (CEPAL) en sus Objetivos de Desarrollo Sustentable $N^{0} 6$, señala Agua limpia y Saneamiento (Organización de las Naciones Unidas [ONU], 2015a) y que la meta es aumentar considerablemente el uso eficiente de los recursos hídricos en todos los sectores y "asegurar la sostenibilidad de la extracción y el abastecimiento de agua dulce" IONU, $2015 b$ ) para hacer frente a la escasez de agua y reducir considerablemente el número de personas que sufren la falta de ésta.
El agua es un recurso natural renovable, del cual la humanidad es absolutamente dependiente. A pesar de ello, hay graves deficiencias en determinar las formas más eficientes de aprovechar el agua sin afectar la sustentabilidad de esta en el largo plazo. La falta de datos sistemáticos limita una evaluación exacta y detallada del alcance del problema y es un obstáculo serio para la gestión de los recursos hídricos. El estado de los recursos hídricos se ha caracterizado mediante el uso de términos como "hidrocidio" (Falkenmark y Lundqvist, 1998), que es la degradación de la calidad del agua hasta el punto en que ya no es apta para un propósito. El término "seguridad del agua" también ha crecido en uso /Cook y Bakker, 20121, como el concepto de "acceso seguro al agua potable" Organización Mundial de la Salud [OMS] y 
Fondo de las Naciones Unidas para la Infancia [UNICEF], 2015).

Dickson, Schuster-Wallace y Newton (2016) señalan que el año 2010 se había logrado el Objetivo de Desarrollo del Milenio, que era reducir a la mitad el número de personas sin acceso a agua potable mejorada, meta fijada para 2015 (OMS y UNICEF, 2012). Sin embargo, más de 740 millones de personas permanecen aún sin acceso a agua potable. Asimismo, el objetivo de saneamiento no se cumplió, dejando a 2,4 mil millones de personas sin saneamiento mejorado. Los que quedan atrás, sin agua y saneamiento básico, tienden a ser pobres y vulnerables, las poblaciones rurales en los países de ingresos bajos y medios (OMS y UNICEF, 2015).

El Programa de las Naciones Unidas para el Ambiente (UNEP), en su informe, Perspectiva del Medio Ambiente Mundial, plantea que el "crecimiento demográfico, la urbanización, la contaminación del agua" y el "desarrollo insostenible" están aumentando la presión sobre los recursos hídricos en todo el mundo, y esa presión se ve exacerbada por el cambio climático. También, existe evidencia que la calidad del agua ha empeorado significativamente desde 1990, debido a la contaminación orgánica y química ocasionada por agentes patógenos, fertilizantes, plaguicidas, sedimentos, metales pesados, desechos plásticos y microplásticos, contaminantes orgánicos persistentes y salinidad (UNEP, 2019).

Frente a este poco alentador diagnóstico, las estrategias de protección del agua tienen que ser promovidas por los entes reguladores del agua o del ambiente lo aquellas agencias, departamentos $u$ oficinas de gobierno nacionales, regionales o locales, encargados de realizar esta función). Sin embargo, también es importante que la atención se focalice a la escala y nivel de detalle de evaluación y protección de fuentes de abastecimiento de agua específicas (Foster, 1987).

Hoekstra (2000), realiza una descripción de algunas de las principales controversias entre los hidrólogos y la gestión política. Estas controversias tienen que ver con preguntas como: ¿Qué factores determinan la demanda de agua? ¿Cuál es el posible papel de la tecnología? ¿Cuánta agua hay disponible? ¿Qué es la escasez de agua? ¿Qué tipo de política adoptar en condiciones de escasez de agua?Para este autor, la fijación de precios del agua, por ejemplo, es sólo una forma particular de apreciar el agua en la sociedad, es decir, a través de los mecanismos de mercado, pero también hay miradas que tienen que ver con cómo se distribuye el agua en la sociedad, es decir, conocer su ciclo hidrosocial, además de su disponibilidad física o ciclo hidrológico (Hoekstra, 2000).

Por otra parte, la toma de decisiones y el desarrollo de políticas públicas eficientes, en materia de recursos hídricos, deben sustentarse en un sistema adecuado de indicadores, por tanto, el establecimiento de indicadores es básico para evaluar la situación de las aguas superficiales y subterráneas, especialmente para proteger su calidad, considerando también aspectos sociales, económicos y ambientales (Vrba et al., 2007). La selección de indicadores está en función de los objetivos perseguidos, por lo tanto, es esencial definirlos en el contexto de la protección de las aguas subterráneas o superficiales y evaluarlos en la escala espacial adecuada. En el proceso de selección de indicadores, se recomienda 
incorporar ideas e intereses de los sectores académicos, gubernamentales y de la sociedad civil (Secretaría del Medio Ambiente y Recursos Naturales de México [Semarnat], 2005).

La Organización de las Naciones Unidas para la Alimentación y la Agricultura (FAO), a través de la Gestión Forestal Sostenible, sostiene que el agua es un elemento esencial de la gestión forestal sostenible y que los bosques son cruciales para regular el ciclo del agua y, de este modo, asegurar la provisión de servicios ambientales, entre ellos la producción hídrica. Un estudio de las 105 ciudades más grandes del mundo, realizado en 2003 para el Fondo Mundial para la Naturaleza y el Banco Mundial, reveló que una tercera parte de las mismas obtiene una cantidad sustancial de su agua potable de cuencas de captación forestales protegidas.

En términos de gestión y a una escala global, la Organización Mundial de la Salud, promueve el Plan Seguridad del Agua (OMS, 2009), como la forma más eficaz de garantizar el abastecimiento de agua, aplicando un planteamiento integral de evaluación y gestión de riesgos que considere todos los elementos del sistema de abastecimiento, entre ellos las ACAP.

\section{II.- SITUACIÓN EN CHILE}

En relación con la disponibilidad del recurso hídrico,

Chile posee 101 cuencas hidrográficas que incluyen 1.251 ríos y 12.784 cuerpos de agua correspondientes a lagos y lagunas. A ellas se suman 24.114 glaciares, los que aportan caudal de escorrentía en el estiaje. Se han delimitado 137 acuíferos y 375 sectores hidrológicos de aprovechamiento común (SHAC) a lo largo del territorio nacional, de los cuales un $47 \%$ se encuentra bajo restricción o prohibición. En términos generales existe un bajo conocimiento del grado de interconexión de los acuíferos, su extensión vertical y horizontal, y su nivel de recarga. (Dirección General de Aguas [DGA], 2016, p.8).
El volumen de agua usado durante el año 2015 en Chile alcanzó un estimado de 10.900 millones de m3, proveniente tanto de fuentes de agua superficial como subterránea (Ministerio de Obras Públicas [MOP], 2020). A su vez, sólo el $6 \%$ es consumido como agua potable, un $73 \%$ se utiliza en la agricultura, 12\% industria y 9\% en minería (MOP, 2012). De acuerdo con la Organización para la Cooperación y el Desarrollo Económicos (OCDE), habrá una creciente presión sobre los recursos hídricos existentes, lo que amenazará la seguridad del acceso al agua (OCDE, 2017). Si bien en nuestro país se ha logrado el acceso casi universal a servicios básicos, el acceso al suministro de agua potable y al saneamiento en algunos asentamientos rurales sigue siendo un desafío. Según la OMS y la UNICEF (2017), actualmente el 7\% de la población rural de Chile carece de acceso a fuentes de agua potable de calidad y el $9 \%$ a servicios de saneamiento e higiene adecuados (OCDE, 2017a). Además, la insuficiencia de datos e información también obstaculizan la eficiencia de las inversiones del Programa del Estado de Proyectos de Agua Potable Rural (OCDE, 2017b; Banco Mundial, 20111.

En términos de gestión de recursos hídricos en Chile, la Constitución Política del Estado (Decreto 100), en su artículo 19, numeral 8 indica: "El derecho a vivir en un medio ambiente libre de contaminación" y que "es deber del Estado velar para que este derecho no sea afectado y tutelar la preservación de la naturaleza". Asimismo, el numeral 24 señala en su primer párrafo: "El derecho de propiedad en sus diversas especies sobre toda clase de bienes corporales o incorporales". Finalmente, en el último párrafo "Los derechos de los particulares sobre las aguas, reconocidos o constituidos en conformidad a la ley, ołorgarán a sus titulares la propiedad sobre ellos". 
Para el Ministerio de Obras Públicas (2020), la política hídrica debe entregar lineamientos para avanzar hacia el uso sustentable de los acuíferos, lo que requiere modelación, información, monitoreo y fiscalización, e incentivos adecuados para el uso y la infiltración artificial". Además, agrega que una política hídrica debe entregar lineamientos para la adecuada protección y restablecimiento de los ecosistemas relacionados con el agua, a través del monitoreo de la salud de los ecosistemas, que alerte de los casos en riesgo y que oriente la intervención directa para su conservación y restablecimiento en donde se pueda alcanzar el mayor impacto (MOP, 20201.

En términos de política pública, uno de los objetivos de la Política Nacional de Recursos Hídricos (Ministerio del Interior, 2015) es: "garantizar a las generaciones actuales y futuras, la disponibilidad y acceso al agua en estándares de calidad y cantidad adecuados mediante el uso racional y sustentable de los recursos hídricos, privilegiando en primer lugar el consumo humano". En dicha política, además, se establece la necesidad de adoptar medidas alternativas de reordenamiento institucional, vinculadas con: la sustentabilidad y protección del agua tanto desde el punto de vista de la cantidad como de la calidad; la articulación de la gestión de los recursos hídricos con el uso del suelo y la gestión de los recursos hídricos a nivel de cuencas hidrográficas. En sintonía con estos principios, Alvarado, Esteller, Quentin y Expósito (2016) identifican tres aspectos o criterios básicos para la protección de la calidad del agua subterránea: el agua subterránea constituye la fuente de suministro más segura e importante para las necesidades humanas; los acuíferos son vulnerables a la contaminación y los principales forzantes son tierras de cultivo, usos industriales y urbanos y se deben proteger las fuentes de agua potable, conformando áreas de protección de pozos y definiendo qué actividades antrópicas son posibles de desarrollar, con un riesgo aceptable para el acuífero.

La crisis hídrica ha obligado a los gobiernos chilenos de la última década a adoptar una serie de medidas de gestión de corto y mediano plazo, incluyendo medidas de emergencia que se han perpetuado a través de los años, como la distribución de agua potable en la región del Biobío y otras regiones del país, con camiones aljibes desde el año 2012. Estas medidas han tenido un enorme costo económico para el Estado y los contribuyentes y no han resuelto el problema de fondo de acceso al agua potable para importantes segmentos de población rural, en un contexto o escenario de prolongada sequía y cambio climático.

\section{III.- SITUACIÓN DE LAS ACAP EN CHILE Y LA REGIÓN DEL BIOBÍO}

En Chile, la vulnerabilidad de las captaciones de agua potable cada día se hace más evidente, registrándose, en los últimos años, varios eventos que han afectado seriamente la provisión de agua potable en varias localidades del país y la región: Río Mapocho (Superintendencia de Servicios Sanitarios, [SISS] 2019a), Región Metropolitana (SISS, 2015a), Osorno (SISS, 2019 b) y Florida (SISS, 2015b). Asimismo, en la región del Biobío son casi 7 mil 500 viviendas abastecidas mediante camión aliibe (ONEMI, 2020). 
En esta investigación se caracterizó y evaluó la de Agua Potable Rural (APR) de la vulnerabilidad de las ACAP de la Región del Dirección Obras Hidráulicas (DOH) y los Biobío, frente a diversas presiones de uso o denominados sistemas de Agua Potable factores forzantes. Para ello se identificaron, Rural Externos que operan en la región del describieron y representaron, espacialmente, Biobío. Todas las ACAP consideradas las ACAP y se estableció un índice de poseen su captación en la región del vulnerabilidad, a escala regional y de Biobío, sin embargo, debido a la subcuenca hidrográfica, que permita orientar extensión territorial de las mismas, partes medidas y acciones de gestión.

\section{IV.- METODOLOGÍA}

\section{1.- ÁREA DE ESTUDIO}

El área de estudio corresponde a las 177 ACAP que conforman las captaciones de agua potable de los sistemas concesionados (SISS, 2021 ), los sistemas de las regiones de Nuble y La Araucanía fueron incluidos en el análisis. La superficie total es de $27.633 \mathrm{~km} 2$, una extensión mayor que la región del Biobío (Resolución 23) o la cuenca del río Biobío (DGA, 2016). La superficie de ACAP en La Araucanía es de 8.083 km2 (29,25\%), Nuble 557 km2 (2,01\%) y 18.990 km2 (68,73\%) en Biobío (Figura 11 .
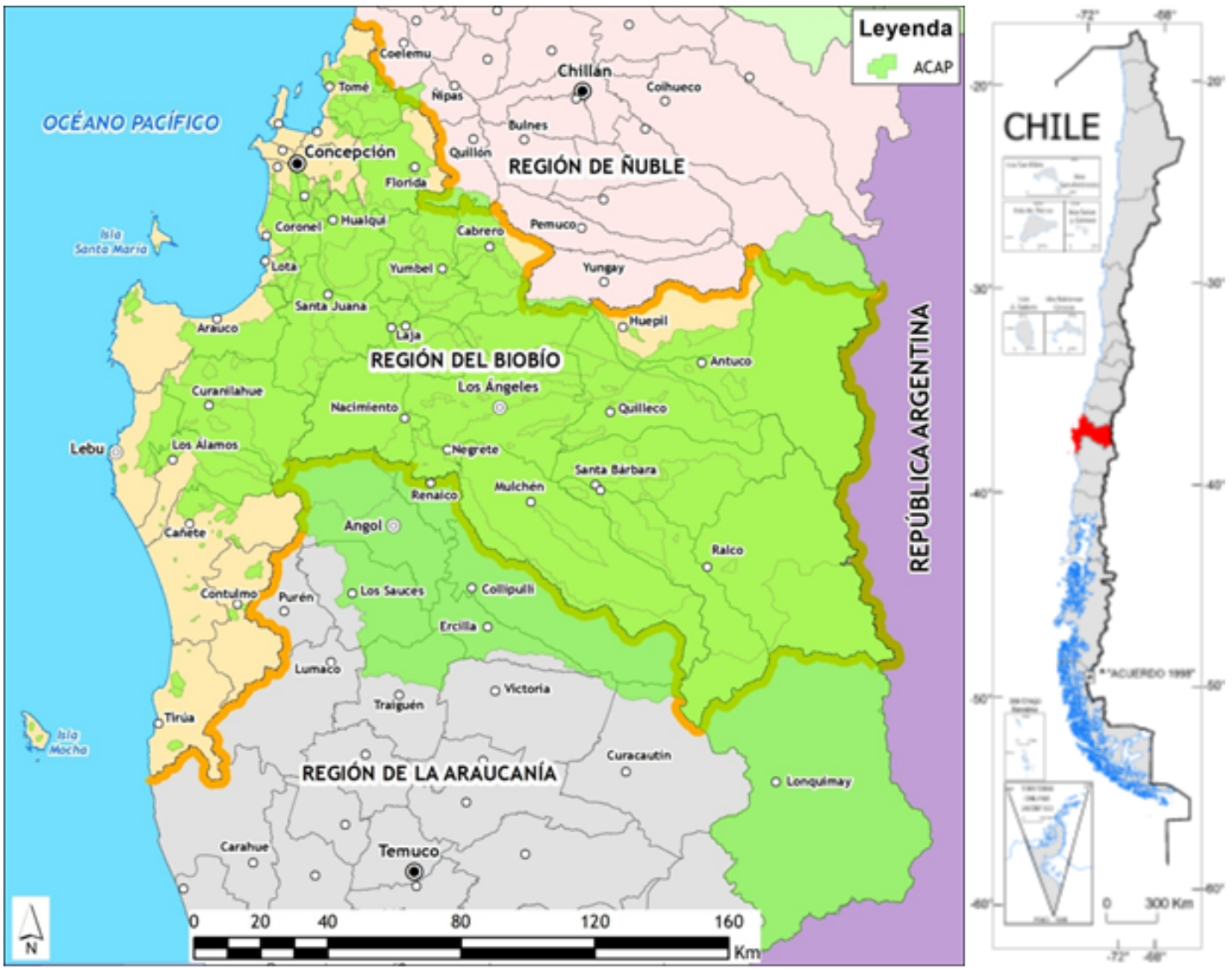

Figura 1. Área de Estudio Fuente: INE (2017) y elaboración propia 


\section{2.- DELIMITACIÓN Y} CARACTERIZACIÓN DE LAS ACAP La caracterización de las ACAP se basó modelo digital de elevación y posterior en la revisión de documentos y proceso en ambiente SIG (ArcGIS) (Figura publicaciones científicas de organismos 2). La información de base para la internacionales y nacionales, como construcción de los diferentes indicadores asimismo reportes e informes de carácter se representó espacialmente (Figura 3).

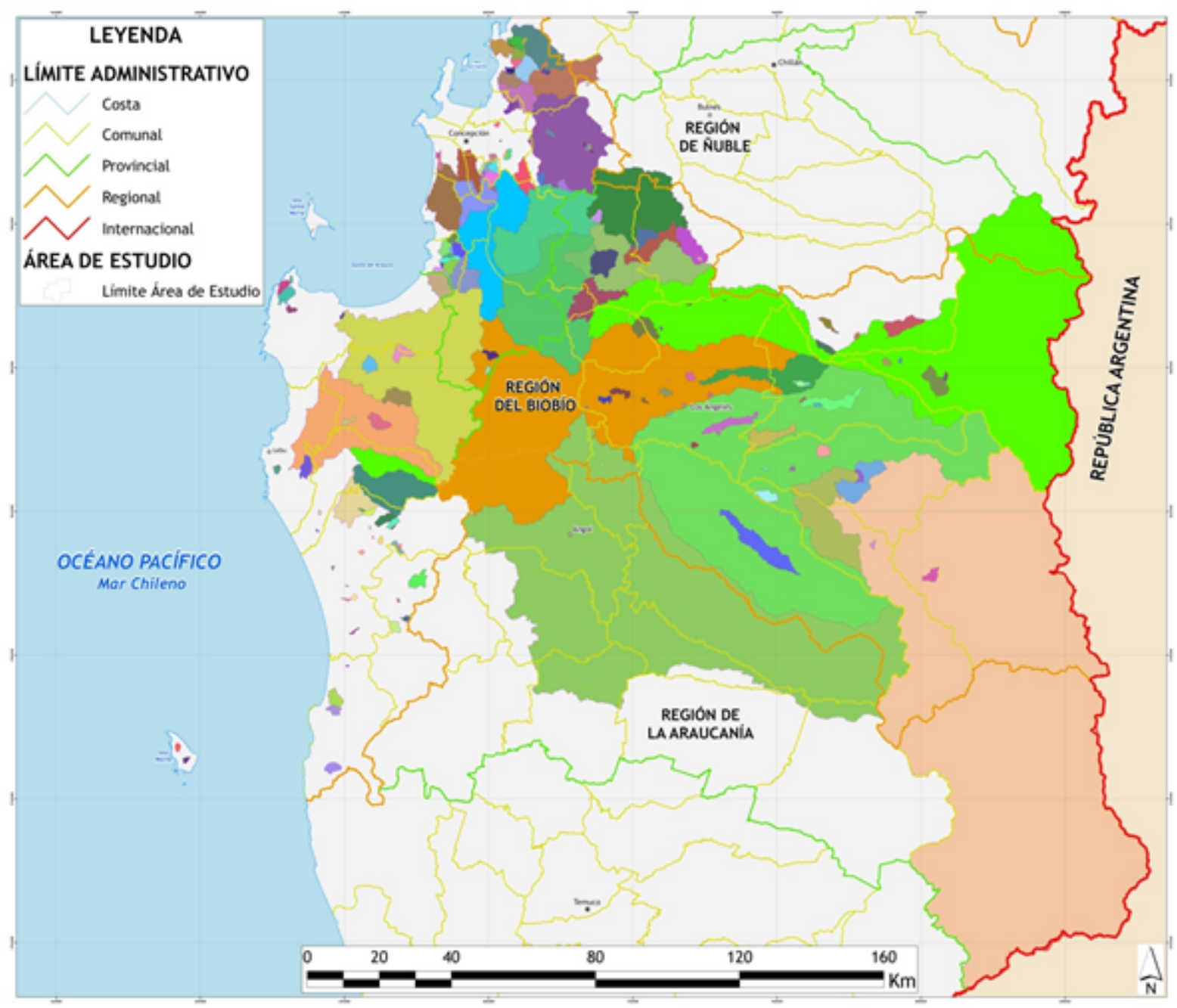

Figura 2. Delimitación y representación de las 177 ACAP región del Biobío Fuente: DOH (2019), SISS (2019c) y elaboración propia 


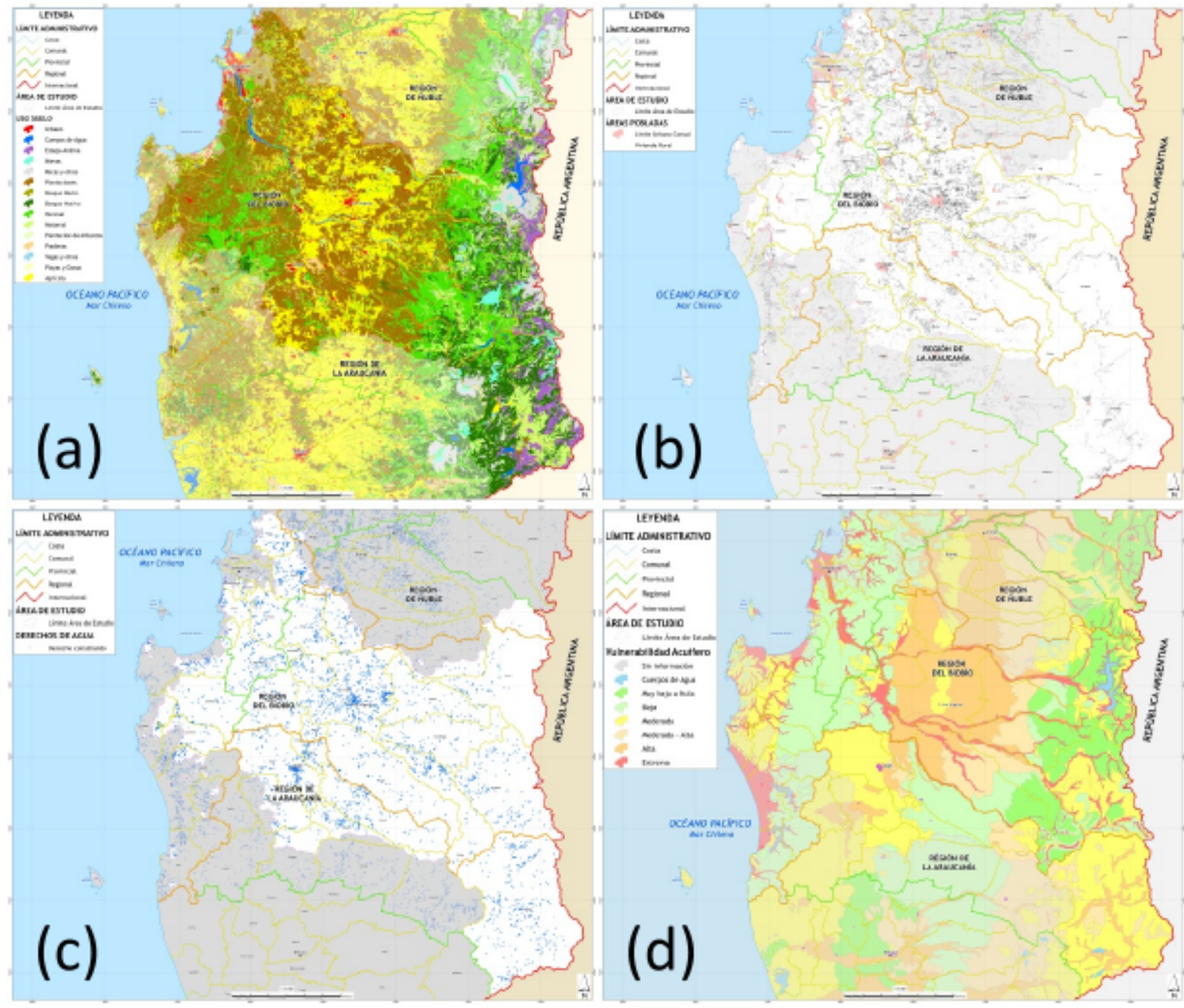

Figura 3. Cartografía información base: a) Uso del suelo, b) Viviendas, c) Derechos de agua y d) Vulnerabilidad del acuífero. Fuente: CONAF (2015), INE (2017), DGA (2019),

SERNAGEOMIN (2006) y elaboración propia

\section{3.- INDICADORES Y FUENTES DE INFORMACIÓN} La construcción del Índice de recopilando el tipo de captación Vulnerabilidad de las ACAP (IV-ACAP) se (superficial o subterráneo), basó en la integración de una serie de emplazamiento (sistema de coordenadas indicadores que reflejan la dinámica WGS 84 huso 18 sur), número de económica, productiva y arranques, volumen y altura del estanque, socio-demográfica que actúan, de manera entre otras características. Mediante el conjunta, sobre un determinado territorio o uso de ArcGIS se elaboró cartografía que ACAP de la región del Biobío (Tabla 1; permitiera delimitar las ACAP, así como Figura 4). Desde el año 2015, se llevaron también todos los mapas temáticos a cabo en terreno actividades de requeridos. Asimismo, se empleó 
información digitalde las cartas IGM manejó en ambiente $S I G$, proceso que 1:50.000 como cartografía base y se facilitó la construcción de los indicadores creó una base de datos alfanumérica y y el cálculo de la vulnerabilidad de las gráfica. Toda la información se ACAP.

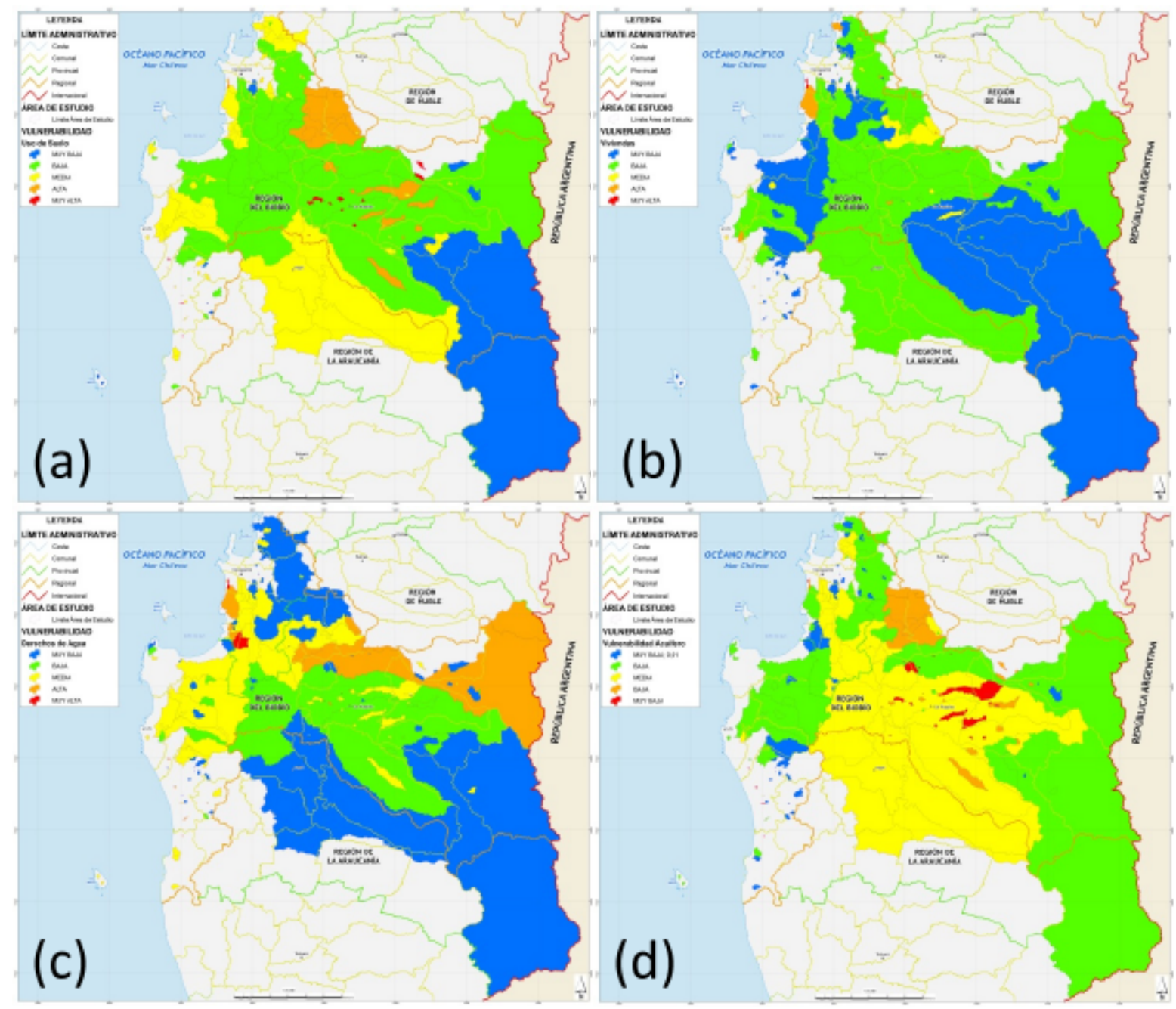

Figura 4. Representación espacial de la vulnerabilidad por ACAP: a) Uso del suelo, b) Viviendas, c) Derechos de agua y d) Vulnerabilidad del acuífero Fuente: elaboración propia 


\begin{tabular}{|c|c|c|c|c|}
\hline Indicador & Objetivo & Descripción & Modo de cálculo & Datos requeridos \\
\hline $\begin{array}{l}1 \quad \text { Indicador de } \\
\text { Uso del Suelo (US) }\end{array}$ & $\begin{array}{l}\text { Identificar y clasificar } \\
\text { la potencialidad } \\
\text { contaminante de las } \\
\text { diversas actividades } \\
\text { de uso de suelo que } \\
\text { se desarrollan en } \\
\text { ACAP. }\end{array}$ & $\begin{array}{l}\text { El uso del suelo se representa } \\
\text { mediante polígonos de } \\
\text { acuerdo a la información } \\
\text { aportada por la Corporación } \\
\text { Nacional Forestal (CONAF) } \\
\text { en el Catastro de Recursos } \\
\text { Vegetacionales Nativos de } \\
\text { Chile de las regiones de } \\
\text { Biobio y La Araucanía. }\end{array}$ & $\begin{array}{l}\text { En cada ACAP y en cada polígono } \\
\text { de uso de suelo se calcula la } \\
\text { superficie (ArcGIS); posteriormente } \\
\text { se calcula el valor ponderado } \\
\text { asociado a cada uso de suelo, } \\
\text { asignando un peso a cada uso de } \\
\text { suelo y de acuerdo a superficie de } \\
\text { cada categoría. Luego, se suman } \\
\text { todos los indicadores ponderados y } \\
\text { se obtiene un coeficiente de uso de } \\
\text { suelo por cada ACAP. Posterior- } \\
\text { mente, y a partir de los resultados } \\
\text { obtenidos, se clasifica la vulnerabili- } \\
\text { dad de las ACAP. }\end{array}$ & $\begin{array}{l}\text { Archivo digital de uso de } \\
\text { suelo del Catastro de Recursos } \\
\text { Vegetacionales Nativos de las } \\
\text { regiones de Nuble, Biobio y } \\
\text { La Araucanía (CONAF, 2015) } \\
\text { y archivo ACAP de este } \\
\text { estudio. }\end{array}$ \\
\hline $\begin{array}{l}\text { 2.- Indicador de } \\
\text { Tamaño de } \\
\text { captación de } \\
\text { agua potable (TA) }\end{array}$ & $\begin{array}{l}\text { Identificar y clasificar } \\
\text { la potencialidad } \\
\text { contaminante de } \\
\text { acuerdo con el } \\
\text { tamaño de cada } \\
\text { ACAP. }\end{array}$ & $\begin{array}{l}\text { El tamaño se representa } \\
\text { mediante polígonos aportado } \\
\text { por el archivo ACAP. Este } \\
\text { archivo es de construcción } \\
\text { propia. }\end{array}$ & $\begin{array}{l}\text { Se calcula en ArcGIS la superficie } \\
\text { en hectáreas y km2 de cada ACAP. } \\
\text { Luego, a cada ACAP se le asigna un } \\
\text { coeticiente de acuerdo con la } \\
\text { superficie obtenida. }\end{array}$ & $\begin{array}{l}\text { Archivo ACAP tipo shapefile } \\
\text { que contiene la superficie de } \\
\text { cada ACAP. Archivo de } \\
\text { construcción propia. }\end{array}$ \\
\hline $\begin{array}{l}\text { 3.- Índice de } \\
\text { Desarrollo } \\
\text { Socio-Económico } \\
\text { (IDSE) }\end{array}$ & $\begin{array}{l}\text { Identificar y clasificar } \\
\text { el Indice de Desarrol- } \\
\text { lo Socio-Económico } \\
\text { de cada ACAP. }\end{array}$ & 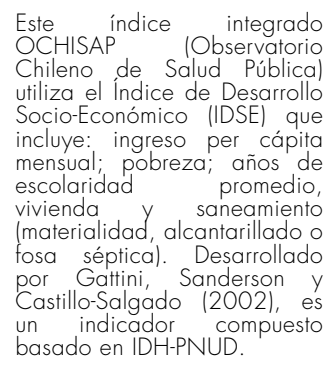 & $\begin{array}{l}\text { Para representar esta variable y } \\
\text { empleando herramientas de ArcGIS, } \\
\text { en cada ACAP se calculó la } \\
\text { superficie que ocupa cada comuna, } \\
\text { posteriormente en una planilla se } \\
\text { ponderó el indicador. Finalmente se } \\
\text { suman todos los indicadores } \\
\text { comunales de cada ACAP que } \\
\text { constituyen el coeficiente. }\end{array}$ & $\begin{array}{l}\text { Archivo digital tipo shapefile } \\
\text { que representa a cada ACAP, } \\
\text { archivo digital de los límites } \\
\text { administrativos e IDSE de } \\
\text { cada comuna. }\end{array}$ \\
\hline $\begin{array}{l}\text { 4.- Indicador de } \\
\text { Densidad de } \\
\text { Viviendas (VIV) }\end{array}$ & $\begin{array}{l}\text { Conocer la densidad } \\
\text { de viviendas que se } \\
\text { encuentran en cada } \\
\text { ACAP. }\end{array}$ & $\begin{array}{l}\text { Se contabilizaron la cantidad } \\
\text { de viviendas rurales y/o } \\
\text { urbanas que se emplazan al } \\
\text { interior de cada ACAP }\end{array}$ & $\begin{array}{l}\text { Con ArcGIS se contabilizaron las } \\
\text { viviendas (rurales y / o urbanas) de } \\
\text { cada ACAP luego en la planilla se } \\
\text { calculó la densidad y se obtuvo un } \\
\text { coeficiente para cada ACAP. }\end{array}$ & $\begin{array}{l}\text { Archivo digital ACAP y Censo } \\
2017 \text {. }\end{array}$ \\
\hline $\begin{array}{l}\text { 5.- Indicador de } \\
\text { Actividades } \\
\text { Antrópicas (AA) }\end{array}$ & $\begin{array}{l}\text { Conocer la densidad } \\
\text { de actividades } \\
\text { antrópicas que se } \\
\text { encuentran en cada } \\
\text { ACAP. }\end{array}$ & $\begin{array}{l}\text { Contabilizar el número de } \\
\text { actividades antrópicas que se } \\
\text { emplazan al interior de cada } \\
\text { ACAP. }\end{array}$ & $\begin{array}{l}\text { En ambiente ArcGIS se contabiliza- } \\
\text { ron las AA por ACAP, luego en } \\
\text { planilla se calculó la densidad y se } \\
\text { obturo un coeficiente para cada } \\
\text { ACAP dividiendo por el número de } \\
\text { AA presentes. }\end{array}$ & $\begin{array}{l}\text { Archivos digitales de diversas } \\
\text { fuentes, como son: INFORR } \\
\text { (Instituto Forestal), MINAGRI } \\
\text { (Ministerio Agricultura), } \\
\text { MINSAL (Ministerio Salud) y } \\
\text { Ministerio del Interior }\end{array}$ \\
\hline $\begin{array}{l}\text { 6.- Indicador de } \\
\text { Densidad Vial } \\
\text { (DV) }\end{array}$ & $\begin{array}{l}\text { Identificar la } \\
\text { densidad vial en } \\
\text { cada ACAP. }\end{array}$ & $\begin{array}{l}\text { La red vial se representa } \\
\text { mediante un archivo digital } \\
\text { vectorial de líneas. }\end{array}$ & $\begin{array}{l}\text { En ambiente ArcGIS se calculó el } \\
\text { número de metros lineales de vías por } \\
\text { cada ACAP, luego en la planilla se } \\
\text { ponderó esa extensión por la } \\
\text { superficie de cada ACAP, de este } \\
\text { modo se obtuvo la densidad vial por } \\
\text { kmz. Posteriormente, y de acuerdo al } \\
\text { intervalo, se asignó un coeficiente a } \\
\text { cada ACAP. }\end{array}$ & $\begin{array}{l}\text { Archivo ACAP y archivo } \\
\text { digital de red vial Precenso } \\
2016 \text {. }\end{array}$ \\
\hline $\begin{array}{l}\text { 7.- Indicador de } \\
\text { Derechos de } \\
\text { Agua (DA) }\end{array}$ & $\begin{array}{l}\text { Identificar mediante el } \\
\text { registro de } \\
\text { aprovechamiento de } \\
\text { derechos de aguas el } \\
\text { uso consuntivo de } \\
\text { agua (litros / segundol } \\
\text { de cada ACAP. }\end{array}$ & $\begin{array}{l}\text { El registro de aprovechamiento } \\
\text { de derechos de agua, } \\
\text { corresponde a una planilla } \\
\text { electronica que gestiona y } \\
\text { pública la DGA (Dirección } \\
\text { General de Aguas). Esta } \\
\text { planilla posee las coordenadas } \\
\text { del punto de aprovechamiento } \\
\text { del recurso. }\end{array}$ & $\begin{array}{l}\text { Una vez cartografiados los derechos } \\
\text { de aprovechamiento en el ambiente } \\
\text { de ArcGIS y empleando el archivo } \\
\text { digital ACAP, se procede a reconocer } \\
\text { el volumen de derechos consuntivos } \\
\text { (//s/km2) en cada ACAP, para luego } \\
\text { obtener un coeficiente para cada } \\
\text { ACAP. }\end{array}$ & $\begin{array}{l}\text { Planilla de derechos de } \\
\text { aprovechamiento de agua en } \\
\text { DGA y archivo ACAP. }\end{array}$ \\
\hline $\begin{array}{l}\text { 8.- Indicador de } \\
\text { Areas Protegidas } \\
\text { (AP) }\end{array}$ & $\begin{array}{l}\text { Identificar las áreas } \\
\text { que cuentan con } \\
\text { protección oficial y } \\
\text { voluntaria en las } \\
\text { ACAP. }\end{array}$ & $\begin{array}{l}\text { Las áreas SNASPE ISistema } \\
\text { Nacional de Areas Silvestres } \\
\text { Protegidas del Estadol y otras } \\
\text { áreas similares constituyen una } \\
\text { porción dentro de las ACAP, } \\
\text { esta información se encuentra } \\
\text { disponible como archivo } \\
\text { digital. }\end{array}$ & $\begin{array}{l}\text { En cada ACAP se calculó la superficie } \\
\text { con algún grado de protección, luego } \\
\text { la superficie se traspasó a una planilla } \\
\text { en la cual se calculó el peso del } \\
\text { indicador que posee cada tipo de } \\
\text { protección. Posteriormente, se sumó el } \\
\text { indicador con protección y el } \\
\text { indicador sin protección, obteniendo } \\
\text { un coeficiente ponderado para cada } \\
\text { ACAP }\end{array}$ & $\begin{array}{l}\text { Archivo digital provisto por } \\
\text { CONAF de las áreas } \\
\text { SNASPE, sitios prioritarios y } \\
\text { área de protección privada } \\
\text { del MMA (Ministerio de } \\
\text { Medio Ambiente) y archivo } \\
\text { ACAP. }\end{array}$ \\
\hline $\begin{array}{l}\text { 9.- Indicador de } \\
\text { Vulnerabilidad del } \\
\text { Acuífero a la } \\
\text { Contaminación } \\
\text { (VAC) }\end{array}$ & $\begin{array}{l}\text { Determinar la } \\
\text { vulnerabilidad del } \\
\text { acuífero a la } \\
\text { contaminación. }\end{array}$ & $\begin{array}{l}\text { Evalúa la vulnerabilidad natural } \\
\text { del acuífero, como función de la } \\
\text { inaccesibilidad de la zona } \\
\text { saturada a la penetración de } \\
\text { contaminantes, y la capacidad } \\
\text { de atenuación de los estratos } \\
\text { localizados sobre la zona } \\
\text { saturada como resultado de su } \\
\text { retención física y la reacción } \\
\text { química con los contaminantes. }\end{array}$ & $\begin{array}{l}\text { En cada ACAP se ponderaron los } \\
\text { distintos tipos de vulnerabilidad para } \\
\text { generar un coeficiente por ACAP, } \\
\text { según las formaciones geológicas } \\
\text { existentes. }\end{array}$ & $\begin{array}{l}\text { Archivo digital denominado } \\
\text { Vulnerabilidad a la contami- } \\
\text { nación de los acuíferos y } \\
\text { Sitios prioritarios para la } \\
\text { conservación de la Biodiversi- } \\
\text { dad: identificación de zonas } \\
\text { críticas. }\end{array}$ \\
\hline
\end{tabular}

Tabla 1. Descripción indicadores Fuente: Elaboración propia. 


\section{4.- INDICADORES Y ANÁLISIS MULTI-CRITERIO (AMC)}

En este estudio se aplicó el Analisis Multi-criterio (AMC) como una herramienta para jerarquizar la prioridad de protección de las ACAP, para ello se seleccionaron los elementos más representativos que pueden ser cuantificados con la información disponible, y que corresponden a los 9 indicadores descritos anteriormente $y$ calculados para 177 ACAP: Indicador Uso de Suelo (US); Indicador Tamaño ACAP (TA); Índice de Desarrollo
Socio-Económico (IDSE); Indicador de Densidad de Viviendas (VIV); Indicador de Actividades Antrópicas (AA); Indicador de Densidad Vial (DV); Indicador Derechos de Agua (DA); Indicador Áreas Protegidas (AP) e Indicador de Vulnerabilidad del Acuífero (VAC). Posteriormente, se procedió a construir una matriz de ponderación de opiniones de un grupo seleccionado de expertos, estos se clasificaron en 5 tipos, que corresponden a las áreas donde se desempeñan laboralmente. Se recibieron 39 matrices debidamente completas. El proceso se llevó a cabo entre abril y julio de 2020 .

\begin{tabular}{|l|c|c|c|c|c|}
\hline \multicolumn{1}{|c|}{ Tipo } & Total & Respondidas & Doctor & Magister & Profesional \\
\hline Academia & 44 & 17 & 6 & 7 & 4 \\
\hline Gremiales & 9 & 3 & - & - & 3 \\
\hline Municipalidad & 7 & 2 & - & - & 2 \\
\hline Públicos & 49 & 13 & 1 & 7 & 5 \\
\hline ONG & 11 & 4 & 1 & 1 & 2 \\
\hline TOTAL & 120 & 39 & 8 & 15 & 16 \\
\hline
\end{tabular}

Tabla 2.Registro de matrices remitidas y respondidas Fuente: Elaboración propia.

La ponderación obtenida dependió del valor que cada convocado, según sus conocimientos y experiencias, le atribuyó a la importancia relativa de cada criterio en la problemática, es decir, la prioridad de protección de las ACAP frente a cada componente que dio origen a un indicador específico de evaluación. La importancia de un factor o componente, colocado en la columna de la matriz, sobre otro ubicado en la fila, se calificó con una escala continua de 9 puntos.

\section{5.- FORMULACIÓN DEL MÉTODO}

DE CÁLCULO ÍNDICE DE VULNERABILIDAD DE ACAP

La agregación de los indicadores se efectuó mediante una combinación lineal ponderada. Se consideraron los pesos relativos de los factores ya obtenidos, para asignar los puntajes de priorización y los resultados del AMC que entregan los pesos asignados a cada indicador. El valor final, entonces, es el resultado de la multiplicación del valor del indicador por el factor de ponderación obtenido del AMC. 
La expresión matemática es la siguiente:

$$
\begin{aligned}
& I V-A C A P=0,0876 U S+0,0851 T A+0,0828 I D S E+0,0883 V I V+ \\
& 0,0888 A A+0,0422 D V+0,1334 D A+0,1271 A P+0,2648 V A C
\end{aligned}
$$

Dónde IV-ACAP = Índice Vulnerabilidad Área de Captación de Agua Potable

* US = Indicador uso del suelo

* TA = Indicador tamaño área captación de agua potable

* IDSE = Índice de desarrollo socio-económico

* VIV = Indicador densidad de viviendas

* $\mathrm{AA}=$ Indicador actividades antropogénicas

* $\quad$ DV $=$ Indicador densidad vial

* $\quad \mathrm{DA}=$ Indicador derechos de agua

* $\quad A P=$ Indicador de áreas protegidas

* $\quad$ VAC $=$ Indicador vulnerabilidad del acuífero a la contaminación

\section{V.- RESULTADOS}

En la Tabla 3 se presentan las principales vulnerabilidad, es decir, a mayorpresencaracterísticas de las ACAP y en la Tabla cia del elemento en la ACAP mayor es su 4 los valores de prioridad promedio, vulnerabilidad, por lo tanto, más prioritarobtenidos para cada indicador y un valor ia su adecuada gestión y conservación. de prioridad promedio de todos los Por el contrario, los menores valores indiindicadores (Tabla 5). Estos resultados can una menor vulnerabilidad. La excepindican que la mayoría de los ción a esta "regla" son los criterios IDSE y indicadores propuestos en este método TA, los cuales no muestran una tendencia muestran una relación lineal con la similar. 


\begin{tabular}{|c|c|}
\hline CRITERIO & DESCRIPCIÓN \\
\hline $\begin{array}{l}\text { Indicador Uso de } \\
\text { Suelo }\end{array}$ & $\begin{array}{l}\text { En el área de estudio se han identificado } 24 \text { usos de suelo. Los cinco usos de } \\
\text { suelo más abundantes son Plantaciones Forestales con } 8.648 \mathrm{~km}^{2}(31,32 \%) \text {, } \\
\text { Bosque Nativo } 7.838 \mathrm{~km}^{2}(28,38 \%) \text {, Rotación Cultivo-Pradera con } 3,130 \mathrm{~km}^{2} \\
\text { (11,33\%), Praderas con } 1.942 \mathrm{~km}^{2}(7,03 \%) \text { y Matorral con } 1.390 \mathrm{~km}^{2}(5,04 \%) \text {. }\end{array}$ \\
\hline $\begin{array}{l}\text { Indicador } \\
\text { Tamaño Área de } \\
\text { Captación de } \\
\text { Agua Potable }\end{array}$ & $\begin{array}{l}\text { La superficie total de las ACAP es de } 27.615 \mathrm{~km} 2 \text {, asimismo la ACAP de menor } \\
\text { extensión sólo tiene } 0,07 \mathrm{~km} 2(6,55 \text { hectáreas), y la de mayor extensión es de } \\
24.091 \mathrm{~km}^{2}\end{array}$ \\
\hline $\begin{array}{l}\text { Índice de } \\
\text { Desarrollo Socio- } \\
\text { Económico }\end{array}$ & $\begin{array}{l}\text { Hay } 47 \text { comunas consideradas en el área de estudio. De acuerdo con el índice } \\
\text { IDSE, } 5 \text { comunas (todas del área metropolitana de Concepción) poseen los } \\
\text { mejores índices, en rango Alto son } 9 \text { comunas, en rango medio } 27 \text {, en rango } \\
\text { bajo } 5 \text { y en muy bajo } 2 \text {. }\end{array}$ \\
\hline $\begin{array}{l}\text { Indicador de } \\
\text { Densidad de } \\
\text { Viviendas }\end{array}$ & $\begin{array}{l}\text { El total de viviendas en las ACAP es de } 268.560 \text { viviendas, de las cuales } 75.762 \\
\text { son rurales y } 192.798 \text { son urbanas. Las densidades en las ACAP, fluctúan entre } 0 \\
\text { y } 1870 \text { viviendas } / \mathrm{km}^{2} \text {. }\end{array}$ \\
\hline $\begin{array}{l}\text { Indicador de } \\
\text { Actividades } \\
\text { Antrópicas }\end{array}$ & $\begin{array}{l}\text { Se ha recopilado información disponible sobre Industria forestal primaria, Catastro } \\
\text { frutícola, plantas de tratamiento de aguas servidas rurales, cementerios, rellenos } \\
\text { sanitarios, registro de emisiones y transferencias de contaminantes. }\end{array}$ \\
\hline $\begin{array}{l}\text { Indicador de } \\
\text { Densidad Vial }\end{array}$ & $\begin{array}{l}\text { En el área de estudio se han contabilizado } 18.965 \mathrm{~km} \text { de red vial. Las } \\
\text { densidades varían entre } 0 \text { (22 ACAP) y 11,5 kilómetros de red vial por cada km². }\end{array}$ \\
\hline $\begin{array}{l}\text { Indicador } \\
\text { Derechos de } \\
\quad \text { Agua }\end{array}$ & $\begin{array}{l}\text { Son } 6.069 \text { los expedientes considerados en el estudio, por un volumen total de } \\
118.216 \mathrm{l} / \mathrm{s} \text { y un volumen de } 948 \mathrm{l} / \mathrm{km}^{2} \text {. El } 81 \% \text { de este volumen es para uso } \\
\text { agropecuario, } 11 \% \text { industrial, } 2 \% \text { minería y sólo el } 6 \% \text { para agua potable (DGA } \\
2016 \text { ). }\end{array}$ \\
\hline $\begin{array}{c}\text { Indicador Áreas } \\
\text { Protegidas }\end{array}$ & $\begin{array}{l}\text { Existen en el área de estudio varias categorías que permiten otorgar diversos } \\
\text { grado de protección, aun así las áreas con protección no supera los } 7.315 \mathrm{~km}^{2} \text {, } \\
\text { en SNASPE son } 2.128 \mathrm{~km}^{2} \text {, Sitios Protegidos } 2.967 \mathrm{~km}^{2} \text {, Reserva de la Biosfera } \\
1.520 \mathrm{~km}^{2} \text {, Área Protección Privada } 700 \mathrm{~km}^{2} \text { y Santuario de la Naturaleza con } \\
0,09 \mathrm{~km}^{2} \text {. }\end{array}$ \\
\hline $\begin{array}{l}\text { Indicador de } \\
\text { Vulnerabilidad } \\
\text { del Acuífero }\end{array}$ & $\begin{array}{l}\text { El área de estudio presenta una configuración de suelos y sustrato geológico } \\
\text { caracterizada por la presencia de zonas con grandes depósitos no consolidados } \\
\text { que favorecen la infiltración del agua lluvia y que es vulnerable frente a los } \\
\text { procesos de contaminación. }\end{array}$ \\
\hline
\end{tabular}

Tabla 3. Síntesis características relevantes ACAP Fuente: Elaboración propia

\begin{tabular}{|c|c|c|c|c|c|c|c|c|c|c|}
\hline $\begin{array}{c}\text { Tipo } \\
\text { Vulnerabilidad }\end{array}$ & US & TA & IDSE & VIV & AA & DV & DA & AP & VAC & $\begin{array}{c}\text { Valor } \\
\text { Indicador }\end{array}$ \\
\hline Muy Baja & 0,038 & 0,041 & $2,00 \mathrm{E}-04$ & 0 & 0 & 0,007 & 0 & $3,00 \mathrm{E}-04$ & 0,118 & $\mathbf{0 , 2 0 4}$ \\
\hline Baja & 0,054 & 0,058 & 0,039 & 0,006 & $6,00 \mathrm{E}-04$ & 0,01 & 0,017 & 0,106 & 0,122 & $\mathbf{0 , 4 1 3}$ \\
\hline Media & 0,057 & 0,051 & 0,04 & 0,019 & 0,01 & 0,018 & 0,039 & 0,119 & 0,147 & $\mathbf{0 , 4 9 9}$ \\
\hline Alta & 0,068 & 0,056 & 0,038 & 0,034 & 0,021 & 0,024 & 0,04 & 0,106 & 0,189 & $\mathbf{0 , 6 0 4}$ \\
\hline Muy Alta & 0,078 & 0,066 & 0,03 & 0,048 & 0,03 & 0,028 & 0,081 & 0,124 & 0,223 & $\mathbf{0 , 7 1 1}$ \\
\hline
\end{tabular}

Tabla 4. Resumen Índice Vulnerabilidad Integrado por tipo de vulnerabilidad.

Fuente: Elaboración propia 
La Tabla 5 presenta los resultados del cálculo del 'Índice de Vulnerabilidad' para las 177 ACAP del área de estudio, presentados en 5 rangos de vulnerabilidad, indicativos de la prioridad de gestión en estos territorios (Figura 5). A partir de estos resultados es posible destacar los siguientes aspectos:

a) Rango Muy Baja (6 ACAP), se ubica exclusivamente en la cuenca el estero Nonguén, dentro del Parque Nacional Nonguén: es un área protegida, no hay viviendas, no hay caminos, no hay extracción de agua (al interior del ACAP), posee usos de suelo que favorecen la sostenibilidad del recurso hídrico, no hay actividades antropogénicas y el sustrato geológico es favorable. Se emplaza en las 2 comunas con mejor IDSE.

b) Rango Baja (47 ACAP), se emplaza en la porción andina sur (6 ACAP), las restantes 41 se emplazan en porciones menores en la cordillera de la costa y Nahuelbuta. Una fracción del territorio posee algún grado de protección, hay presencia de viviendas, red vial y extracción de agua, los usos de suelo son menos favorables para la sostenibilidad de los recursos hídricos, el sustrato geológico es más vulnerable a la contaminación y las comunas en que se emplaza poseen un IDSE medio-alto. En todos los indicadores (salvo TA e IDSE), los valores son mayores.

c) Rango Media 166 ACAP), ocupa predominantemente el valle central, cordillera andina norte, de la costa y Nahuelbuta. Una parte menor del territorio posee algún grado de protección, hay una mayor presencia de viviendas, hay una red
Lel sustrato geológico es aún más vulnerable a la contaminación y las comunas en que se emplaza poseen un IDSE medio. En todos los indicadores /salvo vial mayor, hay una mayor extracción de agua, los usos de suelo son aún menos favorables para la sostenibilidad del agua,e IDSE), los valores son un poco mayores.

d) Rango Alta (35 ACAP), la mayoría se encuentra en el valle central (1 8 ACAP) y un núcleo importante en la subcuenca del río Claro (6 ACAP), 5 ACAP en Arauco, 6 ACAP en Florida y 1 ACAP en Coronel. Una gran parte del territorio no posee ningún grado de protección, hay gran presencia de viviendas, hay una red vial importante, hay extracción de agua, los usos de suelo son menos favorables para la sostenibilidad del agua, el sustrato geológico es más vulnerable a la contaminación y las comunas en que se emplaza poseen un IDSE bajo. En todos los indicadores (salvo TA, IDSE y AP), los valores son aún mayores.

e) Rango Muy Alta (23 ACAP), la mayoría en el valle central (14 ACAP), Arauco 5 ACAP, Florida 1 ACAP, San Pedro 2 ACAP (Lomas Coloradas es la ACAP con mayor vulnerabilidad) y Cabrero 1 ACAP. Una fracción mínima del territorio posee algún grado de protección, la mayor presencia de viviendas, la mayor extensión vial, la mayor extracción de agua, los usos de suelo más desfavorables para la sostenibilidad del agua, el sustrato geológico es muy vulnerable a la contaminación y las comunas en que se emplaza poseen un IDSE muy bajo. En todos los indicadores (salvo IDSE y AP), los valores son los mayores. 


\begin{tabular}{|c|c|c|c|}
\hline Tipo de Vulnerabilidad & Valor & Número ACAP & \% ACAP \\
\hline Muy Baja & 0,204 & 6 & 3,39 \\
\hline Baja & 0,413 & 47 & 26,55 \\
\hline Media & 0,499 & 66 & 37,29 \\
\hline Alta & 0,604 & 35 & 19,77 \\
\hline Muy Alta Total & 0,711 & 23 & 12,99 \\
\hline \multicolumn{2}{|c|}{} & $\mathbf{1 7 7}$ & $\mathbf{1 0 0}$ \\
\hline
\end{tabular}

Tabla 5. Índice Vulnerabilidad ACAP según tipo Fuente: Elaboración propia

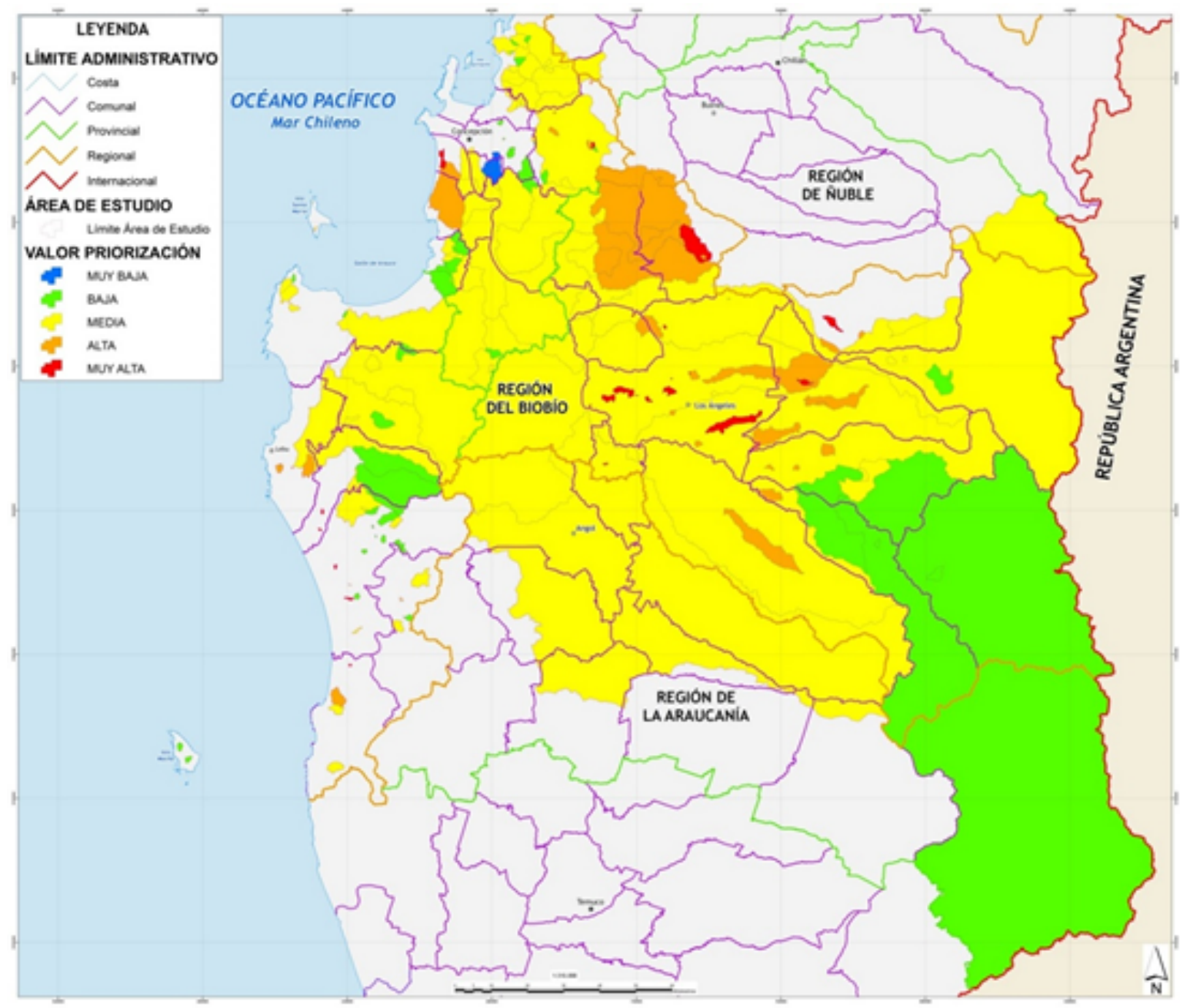

Figura 5. Mapa Índice de Vulnerabilidad de ACAP región del Biobío.

Fuente: Elaboración propia 
La actual y persistente crisis hídrica sugiere la importancia de asegurar, tanto en cantidad como en calidad, el agua potable en las cuencas con mayor prioridad de conservación, es decir, aquellas más vulnerables. De acuerdo al método propuesto, las ACAP con prioridad "Alta" y "Muy Alta" son 58, representan el 30,5\% de las ACAP del área de estudio y se concentran mayoritariamente en 5 sectores de la región, que son los siguientes: Borde costero Pencopolitano, Borde costero Arauco, Subcuenca del río Claro, Valle Central y Cordillera de La Costa. En general en estas ACAP hay un mayor número de viviendas, una extendida red vial, actividades antropogénicas, agrícolas, pecuarias, silvícolas y un intensivo uso del agua con fines agropecuarios. Se considera que los cambios de uso del suelo y, específicamente, la sustitución de vegetación nativa por otras coberturas, representa una seria "amenaza" para la disponibilidad futura de recursos hídricos y la provisión de diversos servicios ecosistémicos, entre ellos la producción de agua potable, tanto en cantidad como calidad.

\section{VI.- DISCUSIÓN}

El análisis territorial y espacial de vulnerabilidades asociadas a las ACAP y representadas a través de un conjunto de indicadores, permite orientar, estratégicamente, la focalización de la inversión pública y la adopción de medidas regulatorias orientadas a reducir la presión de determinadas actividades económicas y presiones de uso sobre importantes cuencas productoras de agua potable. Un aspecto relevante en la gestión del agua potable es o será la capacidad de regular actividades económicas que generan impactos sobre la disponibilidad de recursos hídricos o bien sobre su calidad, como lo es el "sector forestal" industrial y silvícola en la región del Biobío. Se requiere un nuevo enfoque en la planificación y ordenamiento de las zonas rurales, un 'nuevo modelo forestal' que considere el cabio climático y 'ordene el territorio para aminorar externalidades negativas, producir bienes de manera sostenible y crear un ambiente de bienestar' (Organización de las Naciones Unidas para la Alimentación y la Agricultura [FAO], 20151.

A nivel global existen muchos ejemplos, incluso dentro de Sudamérica, de gestión eficiente de agua potable. Uno de los proyectos más ambiciosos está en New York (City's Water Supply System), iniciativa que provee el $90 \%$ del agua 18 millones de consumidores), la cual proviene desde las cuencas de Catskill y Delaware unos 200 km al norte, aporta un caudal de $87,6 \mathrm{~m} 3 / \mathrm{s}$, gestionando un área aproximada de 4.500 $\mathrm{km} 2$, una superficie mayor a la provincia de Concepción y algo menor de la de Arauco. Los 18 millones de habitantes de São Paulo dependen en gran medida de algunas áreas protegidas clave para su agua potable. El principal de ellos es el Parque Estatal Cantareira, de 7.900 hectáreas. La cuenca de Cantareira, ubicada en los remanentes sobresalientes del bosque atlántico altamente amenazado, proporciona el 50 por ciento del suministro de agua al área metropolitana del Gran São Paulo y el Parque Estatal es de importancia central para su protección (Dudley y Stolton, 2003).

En el caso de nuestro país y región del Biobío, un ejemplo relevante de gestión territorial para la producción de agua potable es el Parque Nacional Nonguén. Este parque tiene su origen el año 1911 
cuando se expropiaron los terrenos que conformaban la parte alta de la cuenca del estero Nonguén, zona de captación de agua potable y que abastecería a la ciudad de Penco. Desde ese momento el predio se conocería como "El Fiscal", iniciándose un proceso de recuperación de su vegetación nativa, aspecto que sería fundamental para sostener la producción hídrica de la cuenca, tanto en cantidad como en calidad (Ministerio de Bienes Nacionales, 2002).

Si bien en Chile existen diversas normativas que hacen referencia a la protección de los recursos hídricos, inclusive la necesidad de conocer la "calidad del agua cruda" en captaciones de concesionarias de servicios sanitarios, no hay cuerpos legales que regulen los riesgos antrópicos o naturales a los que puedan estar sometidas las ACAP. En esta línea, la SISS ha estado desarrollando el tema de la seguridad de los abastos de agua, impulsando la implementación de los denominados "Planes de Seguridad del Agua", metodología propuesta por la OMS como una forma de asegurar la calidad del agua a la población frente a las vulnerabilidades que éstas puedan presentar (SISS, 2020). Otras líneas de gestión relevantes son la creación de "distritos de conservación de suelos, bosques y aguas", la mitigación de la contaminación de los acuíferos y la declaración de zonas de "prohibición" de explotación de aguas subterráneas (Biblioteca del Congreso Nacional de Chile [BCN], 20191.

Teniendo en cuenta los antecedentes anteriormente expuestos, la opción de crear distritos de suelo, agua y bosques, aparece como una opción viable, con un claro objetivo de promover la sostenibilidad de las captaciones de agua potable. Sin embargo, aun cuando la normativa está plenamente vigente, desde la promulgación de la misma, nunca se ha constituido un distrito en Chile. Entre las medidas de gestión más importantes identificadas en este estudio, podemos mencionar las siguientes: proponer modificaciones a la Ley General de Urbanismo y Construcción para que puedan ser reconocidas, legalmente, las 'áreas productoras de agua potable' en los instrumentos de planificación; generar distritos de conservación de aguas y suelos; generar nuevos Acuerdos de Producción Limpia (APL), priorizando las ACAP; gestionar con las empresas forestales, mejores prácticas de explotación forestal, limitando la extensión de los rodales a explotar con tala rasa en las ACAP y crear áreas 'renaturalizadas' en la ACAP, que permitan mejorar la sostenibilidad del recurso y educar e informar a la comunidad sobre la importancia de las ACAP, en términos de sostenibilidad del recurso.

Finalmente, es importante disponer de información pública "actualizada" para avanzar en una gestión más eficiente de los recursos hídricos de la región y, en particular, de un enfoque $y$ metodología que permita construir "índices" como el propuesto en esta investigación. En este sentido el IV-ACAP es una herramienta de apoyo a la planificación "estratégica", a diferentes escalas y unidades de análisis, de los recursos hídricos, con enfoque en la provisión de agua potable. 


\section{VII.- CONCLUSIONES}

La gestión de los recursos hídricos plantea nuevas y mayores exigencias a la humanidad. En este estudio se ha logrado identificar 177 ACAP, descritos y representados espacialmente, además se pudo desarrollar un índice que permite jerarquizar a cada ACAP de acuerdo a su rango de vulnerabilidad, en función de ciertos indicadores. Asimismo, se proponen una serie de medidas de gestión que permitirían reducir la 'vulnerabilidad' de las ACAP, especialmente de aquellas más vulnerables. La metodología desarrollada se basa mayoritariamente en registros oficiales de servicios públicos del Estado de Chile, inicialmente demandó un muy importante esfuerzo de sistematización, ordenación y análisis crítico de un conjunto de datos, en algunos casos de difícil acceso y con omisiones. No se trata de un método costoso de implementar y es posible manejar importantes volúmenes de datos a escala regional como de cuencas hidrográficas.

El método de cálculo propuesto para el IV-ACAP entregó un resultado coherente y lógico, en función de la realidad territorial, escala de trabajo y experiencia del investigador. Las medidas de gestión parecen bastante simples de implementar y parecen de toda lógica, sin embargo, se requieren esfuerzos legislativos importantes y la modificación de leyes que regulan la planificación territorial en nuestro país, como es el caso de la Ley $N^{\circ} 18.378$ que promueve la creación de 'distritos de conservación de suelo, bosques y agua'. Una gestión más plausible de implementar es con la industria forestal, su modelo de negocios en el cual la certificación forestal constituye un pilar fundamental, lo hacen más susceptible a este tipo de iniciativa.

\section{REFERENCIAS}

Alvarado, A., Esteller, M. V., Quentin, E., \& Expósito, J. L. (2016). Multi-Criteria Decision Analysis and GIS Approach for Prioritization of Drinking Water Utilities Protection Based on their Vulnerability to Contamination. Water Resources Management, 30(4), 1549-1566. hitps://doi.org/10.1007/s1 1269-016-1239-4

Asamblea General de Naciones Unidas. (2010). Resolución 64/292, El derecho humano al agua y saneamiento. Resolución aprobada por la Asamblea General el 28 de julio de 2010.

Dudley, N., \& Stolton, S. (2003). Running Pure: The importance of forest protected areas to drinking water. World Bank/MWF Alliance for Forest Conservation and Sustainable Use. Recuperado de https:/ /openknowledge.worldbank.org/bitstream/handle/10986/15006/292830RunningOpure .pdf? sequence $=1$ \&isAllowed=y

Banco Mundial (2011). Chile - Diagnóstico de la gestión de los Recursos Hídricos. Recuperado de http://documentos.banc o m und i a l. org/curat ed/es/452181468216298391/ChileDiagn-243-stico-de-la-gesti-243-n-de-los-rec ursos-h-237-dricos

Biblioteca del Congreso Nacional. (2019). Región del Biobío. Chile nuestro país. Recuperado de hitps://wnw.bon.d/siit/nuest ropais/nuestropais/region8/, hiths://ww w.bcn.d/siit/nuestropais/nuestropais/region9/

Comisión Económica para América Latina y el Caribe. (2015). Agenda 2030 para el Desarrollo Sostenible. Recuperado de hitps://wnw.cepal.org/es/temas/agenda2030-desarrollo-sostenible. 
Constitución Política de la República de Falkenmark, M., \& Lundqvist, J. (1998). Chile [Const] Art. 19, 8. Texto actualizado Towards water security: political a octubre de 2010 (Chile).

Cook, C., \& Bakker, K. (febrero, 2012). Water security: debating an emerging paradigm. Global environmental change, $22(1)$, 94-102. Doi https://doi.org/10.1016/i.gloenvcha.2011.10.011.

Corporación Nacional Forestal. (2015). Catastro vegetacional. Recuperado de $\mathrm{h}+\mathrm{t} \mathrm{ps}$ : / / s i t. c o n a f.cl/ https://mww.conaf.cl/nuestros-bosques/bos ques-en-chile/catastro-vegetacional/ https://mww.conaf.cl/parques/reserva-naci onal-nonguen/.

Decreto 100 del 2005. Diario oficial de la República de Chile, Santiago, Chile, 22 septiembre 2005.

Dirección General de Aguas. (2016). Atlas del Agua. Recuperado de https://biblioteca.digital.gob.cl/bitstream / ha n dle/123456789/1382/Atlas201 bparte 1-17 marzo2016b.pdf? sequence $=1$ \&isAllowed $=y$.

Dirección General de Aguas. (2019). Registro de derechos de agua. Recuperado de https://dga.mop.gob.cl/productosyservicios/derechos_historicos/Paginas/default.aspx.

Dickson, S. E., Schuster-Wallace, C. J. \& Newton, J. J. (2016). Water Security Assessment Indicators: The Rural Context. Water resources management, 3015), 1567-1604. Doi: https://doi.org/10.1007/s $11269-016-1254-5$.

Dirección de Obras Hidráulicas, Sistemas de Agua Potable Rural (APR). Recuperado de http://www.doh.gov.cl/APR/AcercadeAPR /Paginas/acercaAPR.aspx, . determination and human adaptation crucial. En Natural Resources Forum (Vol. 22, No. 1, pp. 37-511. Oxford, UK: Blackwell Publishing Ltd.

Foster, S. S. D. (1987). Fundamental Concepts in Aquifer Vulnerability Pollution Risk and Protection Strategy. En Van Duijvenbooden, W. y Van Waegeningh, H.G., (eds.), Proceedins and information in vulnerability of soil and groundwater to pollutants (pp. 69-86). La Haya: Committee on Hydrological Research.

Gattini C., Sanderson C. y Castillo-Salgado C. (2002), Variación de los indicadores de mortalidad evitable entre comunas chilenas como aproximación a las desigualdades de salud. Pan American Journal of Public Health vol. $12 \mathrm{~N}^{\circ} 6$ Washington Dic. 2002. Recuperado de https: / / scielosp.org/pdf/rpsp/2002.v12n6/454-461/es

Hoekstra, A. Y. (marzo, 2000). Appreciation of water: four perspectives. Water policy, volumen (1). Doi: https://doi.org/10.1016/S1366-70171 99100013-6

Instituto Nacional de Estadísticas. (2017). Servicio de Mapas del Censo 2017. Recuperado de http: / / www.censo2017.cl/servicio-de-mapas/

Ministerio de Bienes Nacionales. (2002). Estudio Básico Zonificación Fundo Nonguén, resumen ejecutivo. Convenio Centro EULA-Chile-SEREMI de Bienes Nacionales Región del Biobío, Universidad de Concepción, Concepción, Chile. 
Ministerio de Obras Públicas. (2012), de Herramientas para la Gestión Forestal Estrategia Nacional de Recursos Hídricos Sostenible. (2015). Recuperado de 2012-2025. Recuperado de https://ww- http://wmw.fao.org/sustainable-forest-mana w. m o p.cl/ D o c u m e n t s/E N - gement/toolbox/modules/forest-and-water/b RH_2013_OK.pdf asic-knowledge/es/

Ministerio de Obras Públicas. (2020). Organización de las Naciones Unidas. Mesa Nacional del Agua. Primer informe. (2015a). Objetivos de Desarrollo Recuperado de https://www.infraestructur- Sostenible. Recuperado en https://wwa publica.cl/wp-con tent/up-w.un.org/sustainabledevelopment/es/obloads/2020/03/Mesa_Nacional_del_A jetivos-de-desarrollo-sostenible/ gua_2020_Primer_Informe_Enero.pdf

Ministerio del Interior. (2015). Política Organización de las Naciones Unidas. Nacional de Recursos Hídricos. Recuperado de https://www.interior.gob.cl/media/2015/04/recursos_hidricos.pdf

Organización para la Cooperación y el Desarrollo Económico. (2017a). Análisis de gobernanza de infraestructura: Chile Brechas y estándares de gobernanza de la infraestructura pública en Chile. Mensajes Claves. Editorial OECD. Recuperado

de https://www. oecd.org/gov/budgeting /brechas-y-estandares-de-gobernanza-dela-infraestructura-publica-en-chile.pdf

Organización para la Cooperación y el Desarrollo Económico. (2017b). Brechas y estándares de gobernanza de la infraestructura pública en Chile: Análisis de Gobernanza de la Infraestructura. OECD Publishing, Paris. Doi: https://doi.org/10.1787/9789264286948-es.

Oficina Nacional de Emergencia del Ministerio del Interior. (2020). Reporte beneficiarios camión aljibe comunas de la región del Biobío. Planilla registro único de beneficiarios. ONEMI, Concepción.

Organización de las Naciones Unidas para la Alimentación y la Agricultura. Conjunto (2015b). Objetivo 6: Garantizar la disponibilidad de agua y su gestión sostenible y el saneamiento para todos. https://www.un.org/sustainabledevelopm ent/es/water-and-sanitation/

Organización Mundial de la Salud y UNICEF. (2012). Progress on drinking water and sanitation: 2012 Update. Organización Mundial de la Salud. Recuperado de http://www.mondialisations.org/medias/pdf/drinkingwateren.pdf

Organización Mundial de la Salud y UNICEF. (2015). Progress on Sanitation and Drinking Water; 2015 Update and MDG Assessment. Recuperado de https://www.who.int/water_sanitation_he alth/publications/imp-2015-update/en/

Organización Mundial de la Salud y UNICEF. (2017). Progress on drinking water, sanitation and hygiene: 2017 update and SDG baselines. Recuperado de https://washdata.org/sites/default/files/ documents/reports/2019-05/JMP-2017-r eport-final.pdf

Resolución 23. Diario oficial de la República de Chile, Santiago, Chile, 15 enero 2019. 
Secretaría del Medio Ambiente y Recursos Naturales. (2005). Indicadores básicos de desempeño ambiental 2005. (240 pp) Secretaría de Medio Ambiente y Recursos Naturales. México, D. F.

Servicio Nacional de Geología y Minería. (2006). Vulnerabilidad a la contaminación de los acuíferos y Sitios prioritarios para la conservación de la Biodiversidad: identifi- Superintendencia de Servicios Sanitaricación de zonas críticas. Escala os (Abril de 2021). Concesiones sani1:500000. Recuperado de http://tien-tarias. Recuperado de http://www. da.sernageomin.cl/tiendavirtual2/Product- siss.gob. cl/586/w3-propertyvalDetail.aspx? pid $=2331$.

Superintendencia de Servicios Sanitarios (30 de enero 2019a). Intendenta Rubilar califica como "especialmente vulnerable" a la cuenca del Río Mapocho ante aumento de fenómenos de contaminación del cauce" Recuperado de https://www.siss.gob.$\mathrm{cl} / 586 / \mathrm{w3}$-article-17366.html

Superintendencia de Servicios Sanitarios. (15 de julio de 2019b). Superintendente (s) Rivas hace balance de la situación en Osorno. Recuperado de http://www.siss.gob.cl/586/w3-article-17538.html

Superintendencia de Servicios Sanitarios. (2019c). Recuperado de http://www.siss.gob.cl/586/w3-article-7838.html

Superintendencia de Servicios Sanitarios. (26 de marzo de 2015b). Superintendente (s) de Servicios Sanitarios se reúne con alcalde de Florida para abordar problemas de calidad de servicio en la comuna. Recuperado de htp://www.siss.gob. cl/586/w3-article-1 1576.html
Superintendencia de Servicios Sanitarios. (23 de diciembre de 2015a) Superintendencia de Servicios Sanitarios (SISS) inspecciona corte de suministro de emergencia que afecta a 77 mil clientes de la Región Metropolitana. Recuperado de https://www.siss.gob.cl/586/w3-article$12161 . \mathrm{html}$

ve-6392.html

Superintendencia de Servicios Sanitarios. (2020) Plan Estratégico Nacional. Para la reducción del riesgo de desastres en el sector sanitario 2020-2030 Recuperado de https: //www.siss.gob.cl/586/articles-9353_Plan_Estrategico.pdf Programa de las Naciones Unidas para el Medioambiente (2019), United Nations Environment Programme (Perspectivas del Medio Ambiente), GEO-6, 2019, Página 16. Recuperado de https://wedocs.unep.org/bitstream/handle/20.500.1 1822/27652/GEO6SPM_SP.pdf? sequence=6\&isAllowed $=\mathrm{y}$

Vrba, J., Girman, J., van der Gun, J., Haie, N., Hirata, R., Lopez-Gunn, E., \& Wallin, B. (2007). Groundwater resources sustain ability indicators (p. 1 14). A. Lipponen (Ed.). Paris: Unesco.

Organización de las Naciones Unidas para la Educación, la Ciencia y la Cultura. (20 14). IHP-VI, Serie Aguasubterránea No. 14. UNESCO (pp. 123). Paris. 